to antagonism and stalemate. In the treatment of Singaporean patients, we determine whether they sought traditional healers (often they would volunteer this information). While we do not forbid them from continuing to do so, nor disagree with their beliefs, we do explain to them the concept of the Western model of mental illness, so as to improve compliance with psychiatric medication.

DAvid, A. S. (1990) Insight and psychosis. British Journal of Psychiatry, 156, 798-808.

SALLEH, M. R. (1989) The consultation of traditional healers by Malay patients. Medical Journal of Malaysia, 44, 3-13.

WING, J. K., COOPER, J. E. \& SARTORIUS, N. (1974) Measurement and Classification of Psychiatric Symptoms. Cambridge: Cambridge University Press.

Department of Psychological Medicine

National University Hospital

Lower Kent Ridge Road

Singapore 0511

\section{Clozapine and NMS}

SIR: Some patients given neuroleptics after recovering from neuroleptic malignant syndrome (NMS) have not experienced a recurrence of the syndrome (Meltzer, 1973; Rosebush et al, 1989; Pope et al, 1991), although others have (Buckley et al, 1991). The risk of recurrence of NMS may be reduced by allowing two weeks between the episode of NMS and the reintroduction of neuroleptics, by the gradual titration of neuroleptic dosage, and by termination with early signs of a recurrence. The choice of neuroleptic drug is less clear, and rechallenge with the same typical neuroleptic drug, or an agent of a different chemical structure, appears unrelated to the risk of recurrence of NMS (Buckley et al, 1991).

While the recent report by Weller \& Kornhuber (Journal, December 1992, 161, 855-856) concerning the absence of an NMS recurrence in eight of their nine patients treated with clozapine as a rechallenge agent is encouraging, it is nevertheless premature to suggest that NMS, by itself, provides sufficient clinical indication for clozapine therapy. This is not significantly better than the results in other series (Rosebush et al, 1989; Pope et al, 1991). The other significant side-effects associated with clozapine therapy for treatment-refractory schizophrenia especially agranulocytosis (Meltzer, 1992), the ability of clozapine itself to induce NMS, and the potential for diagnostic confusion between fever, hypo- or hypertension, tachycardia, and comparable effects in NMS - suggest that an episode of NMS is not a sufficient reason to justify a trial of clozapine. Treatment-resistance and intolerance of any neuroleptic drug (e.g. severe tardive dyskinesia or dystonia) are the key indications in schizophrenia for clozapine therapy.

Buckley, P., Freyne, A., McCarthy, A., et al (1991) Neuroleptic malignant syndrome - a follow-up study. Irish Journal of Medical Science, 160, 45-47.

MeLtZER, H. Y. (1973) Rigidity, hyperpyrexia and coma following fluphenazine enthanate. Psychopharmacologia, 29, 337-346.

- (1992) Dimensions of outcome with clozapine. British Journal of Psychiatry, 160 (suppl. 17), 22-29.

Pope, H. G. JR, Aizley, H. G., KeCK, P. E. JR, et al (1991) Neuroleptic malignant syndrome: long-term follow-up of 20 cases. Journal of Clinical Psychiatry, 52, 208-212.

Rosebush, P. I., STEwart, T. D. \& GelenberG, A. J. (1989) Twenty neuroleptic rechallenges after neuroleptic malignant syndrome in 15 patients. Journal of Clinical Psychiatry, 50, 295-298.

\section{Peter F. BuCKLeY} Herbert Y. MELTZER

Department of Psychiatry

Case Western Reserve University

2040 Abington Road

Cleveland, Ohio 44106, USA

\section{In defence of clozapine}

SIR: I feel that Dr Healy's excellent and thoughtprovoking 'Devil's advocate' piece about clozapine should not pass without a few further comments to add to Drs McKenna \& Bailey's cogent defence (Journal, January 1993, 162, 23-29 and 32-37 respectively). In condemning clozapine, Dr Healy uses some misplaced logic and reinterpretation of published findings.

Firstly, the comparisons with other treatments are not really relevant. Coronary artery bypass surgery is no longer a dilemma. It was introduced before the advent of calcium-channel blockers and orally absorbable long-acting nitrates and indeed, for a while, was an expensive but realistic option for treatment. With the advent of pharmacological alternatives, no cardiologist would advocate such expensive treatment in advance of cheaper drug treatment, unless there was an immediate lifethreatening indication (e.g. main stem disease). Similarly, the analogy with newer oncological drugs is misplaced. The circumstances surrounding their use means, unlike clozapine, they are essentially untested treatments often tried as a last resort. At best, they may go through open familiarisation trials in very sick patients. It is usually late on in the drugs' lifespan that they would go through rigorous testing.

Perhaps more meaningful comparisons would be with a 'budget-busting' drug such as cyclosporin, 